\title{
A SIMULAÇÃO ASSISTIDA POR COMPUTADOR: A CONVERGÊNCIA NO PROCESSO DE EDUCAR-CUIDAR DA ENFERMAGEM ${ }^{1}$ COMPUTER-ASSISTED SIMULATION: CONVERGENCE IN THE PROCESS OF EDUCATION AND CARE IN NURSING \\ LA SIMULACIÓN ASISTIDA POR LA COMPUTADORA: LA CONVERGENCIA EN EL PROCESO DE EDUCAR-CUIDAR EN LA ENFERMERÍA
}

\author{
Grace T. M. Dal Sasso ${ }^{2}$, Maria de Lourdes Souza ${ }^{3}$
}

\begin{abstract}
${ }^{1}$ Este estudo é parte da tese denominada "A concepção do enfermeiro na produção tecnológica informatizada para o ensino/aprendizagem em reanimação cárdio-respiratória”, de autoria de Grace Teresinha Marcon Dal Sasso, apresentada ao Programa de Pós-Graduação em Enfermagem da Universidade Federal de Santa Catarina (UFSC), como parte dos requisitos para a conquista do título de Doutor.

${ }^{2}$ Enfermeira. Doutora em Enfermagem. Professora Adjunto 1 dos cursos de Graduação e Pós-Graduação do Departamento de Enfermagem da UFSC. Vice-líder do Grupo de Pesquisa em Estudos Convergente-Assistenciais em Saúde e Enfermagem (GIATE). ${ }^{3}$ Enfermeira. Doutora em Saúde Pública. Professora do Programa de Pós Graduação em Enfermagem da UFSC. Coordenadora Geral da Rede de Pós-Graduação em Enfermagem da Região Sul (REPENSUL).
\end{abstract}

PALAVRAS-CHAVE: Informática em saúde. Enfermagem. Simulação por computador. Educação.

KEYWORDS: Health informatics. Nursing. Computer simulation. Education.

PALABRAS CLAVE: Informática en el salud. Enfermería. Simulación por la computadora. Educación.

RESUMO: Produção tecnológica e pesquisa metodológica que objetivou descrever a produção de um ambiente simulado de aprendizagem assistida por computador em RCP e refletir sobre as suas contribuições no processo ensino-aprendizagem dos alunos como uma proposta de convergência ao processo de educar-cuidar em enfermagem. Á medida que o ambiente de aprendizagem simulado era desenvolvido, procediam-se as avaliações das etapas de produção no processo da pesquisa metodológica, mediante instrumentos específicos. O plano de organização e a análise da produção tecnológica foi fundamentado no referencial construtivista e seguiu os passos da pesquisa metodológica para o desenvolvimento do ambiente simulado. $\mathrm{O}$ estudo enfatiza que, como mediador entre o sujeito e o mundo real, o ambiente simulado de aprendizagem assistida por computador, constitui-se em uma espécie de lente através da qual o aluno é capaz de ver a realidade simulada e operar sobre ela. É proporcionado ao aluno uma oportunidade nova e estimulante de aprendizagem.

ABSTRACT: This article is a methodological study and technological production with the objective to describe the production of a simulated environment of computer-assisted learning in CPR and to reflect on its contributions in the teaching-learning process of students as a proposal of convergence to the educational-care process in nursing. To the degree that the simulated learning environment was developed, the evaluations proceeded from the stages of production in the process of the metodological research by means of specific instruments. The organizational plan and analysis of the technological production was based on the Constructive Framework and followed the steps of methodological research for development of a simulated environment. The study emphasizes that as a mediator between the citizen and the real world, the simulated environment of computer- assisted learning consists of a species of lenses through which the student is capable of seeing the simulated reality and operating within it. It proportionates to the student a new and stimulating opportunity for learning.

RESUMEN: La producción tecnológica y la investigación metodológica con el objetivo de describir la producción de un ambiente simulado de aprendizaje auxiliado por la computadora en el RCP y reflexionar a cerca de sus contribuciones dentro del proceso de enseñanza-aprendizaje de los educandos como una oferta de convergencia en el proceso educar-cuidar en la enfermería. A medida que el ambiente simulado de aprendizaje fue desarrollado, se procedía a evaluaciones de las etapas de producción en el proceso de la investigación metodológica por medio de instrumentos específicos. El plan de la organización y el análisis de la producción tecnológica fue basado en el referencial del constructivismo y siguió los pasos de la investigación metodológica para el desarrollo del ambiente simulado. El estudio destaca, como mediador entre el ciudadano y el mundo verdadero, el ambiente simulado de aprendizaje por la computadora consiste en una especie de lente con la cual el alumno educando es capaz de ver la realidad simulada y operar sobre ella. Proporcionándose al alumno una oportunidad nueva y estimulante de aprendizaje.

Endereço: Grace T. M. Dal Sasso

Av. Gov. Ivo Silveira, 177, Boulevard Hercílio Luz, Ap. 502

88.085-001 - Estreito, Florianópolis, SC.

E-mail: grace@matrix.com.brou grace@nfr.ufsc.br
Artigo original: Pesquisa

Recebido em: 17 de novembro de 2005. Aprovação final: 28 de abril de 2006. 


\section{INTRODUÇÃO}

A Reanimação Cárdio-Pulmonar (RCP) é uma situação na qual as habilidades, os conhecimentos e as experiências das enfermeiras são rigorosamente testadas, uma vez que o desempenho efetivo na cena e os resultados são imediatamente avaliados. É um momento que gera tensão elevada, independentemente da experiência que se tenha, pois cada situação é única e, ao mesmo tempo, paradoxal, pois, embora seja a morte a única certeza que se tem desde o nascimento, a busca de alguns minutos a mais torna a idéia de prolongar a vida uma preocupação eterna e universal no cotidiano das pessoas. ${ }^{1}$

A tensão gerada em uma situação de Parada Cárdio-Respiratória (PCR) muitas vezes, inibe e dificulta o desempenho profissional e a aprendizagem durante os procedimentos exigidos. Além disso, a dinâmica e a constante evolução do conhecimento científico e tecnológico requer dos profissionais de saúde atualizações permanentes sobre as técnicas de reanimação cárdio-pulmonar.

O crescente avanço científico e tecnológico em saúde e educação gera a necessidade de os profissionais buscarem intensa atualização e a informática em Enfermagem se constitui na combinação da ciência da computação, da ciência da informação e da ciência da enfermagem que contribui ao desenvolvimento da educação e do cuidado de enfermagem. ${ }^{2}$

Como educadores, tem-se refletido e buscado, ao longo dos anos, tecnologias que levem em consideração os novos cenários mundiais que sinalizam mudanças no processo ensino-aprendizagem, bem como no paradigma científico que influencia a educação. ${ }^{3}$ Entende-se, portanto, que não se pode mais aprender "com e em vidas humanas", ou seja, especificamente em relação a aprendizagem em RCP a informática emerge como uma oportunidade para aprender a cuidar em enfermagem sem ocasionar riscos à pessoa vítima de uma Parada Cárdio-Pulmonar.

A ética inserida neste processo desencadeia uma revisão de valores e modos de trabalhar a educação no processo de construção do saber, desde o modo como concebemos a academia, até em como pensamos, conhecemos e apreendemos o mundo. Estamos vivenciando um novo tipo de gestão social do conhecimento, apoiado em um modelo que é corrigido e interpretado de forma interativa, na qual o aluno é produtor do seu próprio processo de ensino-aprendizagem. Estes aspectos requerem, portanto, uma nova abordagem educacional, mais atualizada e coerente com as novas demandas da sociedade. ${ }^{4}$

A aprendizagem e a educação se movem entre pólos, dependendo dos métodos e das suposições com o qual cada pessoa se baseia para favorecer estes processos. Coexistem deste modo, duas formas sistemáticas para a criação e uso de ambientes de aprendizagem: o enfoque algorítmico e o enfoque heurístico. ${ }^{4}$

Visando alcançar uma educação que possa ser construtiva e controlada pelo aluno, na qual este poderá usar o computador para desenvolver e provar seus próprios modelos de pensamento é preciso que o educador utilize uma série de estratégias heurísticas baseadas em psicologia cognitiva, que promovam o desenvolvimento da capacidade de autogestão do ato de aprender, tais como: aprender a lidar com os fracassos; distinguir entre transmitir a experiência acumulada e transmitir os modelos (interpretações) desta experiência; esperar o inesperado sobre autogestão educativa, dando ao aluno a oportunidade de percorrer por si mesmo o caminho; usar ambientes educativos ricos, com propósitos claros e bem definidos. ${ }^{4}$

É fundamental que os profissionais busquem a educação e a qualificação continuamente para desenvolver competências e obter conhecimento no tempo certo e com os métodos educacionais adequados. E, neste sentido a Simulação Assistida por Computador é fundamental e adequada para oportunizar cenários de aprendizagem e cuidado em RCP, o que decorre na convergência do educar-cuidar em enfermagem.

A simulação em RCP assistida por computador é entendida neste estudo como uma representação da estrutura ou dinâmica de um objeto real ou processo com o qual o aluno interage ativamente. Por exemplo, o aluno, participante ativo de seu processo ensinoaprendizagem, aplica previamente o conhecimento aprendido para responder (decisões e ações) a um problema ou situação, e recebe feedback sobre as respostas, ou seja, raciocinando e decidindo mediante informações sem o stress da situação real. Dessa forma, as simulações representam uma oportunidade para o aluno assumir um papel e ver as conseqüências de suas ações, em um cenário virtual com o desenvolvimento de competências reais.

Este estudo objetiva descrever a produção de um ambiente simulado de aprendizagem assistida por computador em RCP e refletir sobre as suas contribuições no processo ensino-aprendizagem dos alunos como uma proposta de convergência ao processo de educar-cuidar em enfermagem. 


\section{METODOLOGIA}

Realizou-se uma produção tecnológica e pesquisa metodológica, adotando-se instrumentos estruturados e específicos de avaliação para o aluno de graduação, o enfermeiro, o médico e o programador de sistemas. ${ }^{5}$ Por se tratar de uma produção tecnológica concomitante à pesquisa metodológica, à medida que o ambiente de aprendizagem simulado era desenvolvido, procediamse as avaliações qualitativas e quantitativas das etapas de produção no processo da pesquisa metodológica.

Quanto aos aspectos éticos, todas as etapas da pesquisa foram delimitadas pelos princípios da beneficência, não maleficência, justiça e autonomia, garantindo, portanto o sigilo e anonimato dos participantes, conforme abordados na Resolução específica do Conselho Nacional de Saúde e os princípios do Código de Ética profissional brasileiro. ${ }^{6} \mathrm{O}$ projeto de pesquisa obteve consentimento formal dos participantes, da Universidade e Instituição Hospitalar onde foi desenvolvido, além de ser submetido ao parecer do Comitê de Ética em pesquisa da Universidade Federal de Santa Catarina.

O plano de organização e análise da produção tecnológica foi fundamentado no referencial construtivista $^{7-9}$ e seguiu os passos da pesquisa metodológica para o desenvolvimento de um ambiente simulado inteligente de aprendizagem em RCP: análise das necessidades dos alunos (conteúdo e objetivos); escrita e desenho das instruções (Storyboard); desenvolvimento da multimídia e programação; prova piloto (teste), revisão e modificação. ${ }^{10-15}$

Este processo é dinâmico e a cada etapa de desenvolvimento novas modificações foram desenvolvidas. Salienta-se que esta produção se constituiu em um ambiente tutorial no qual, de forma autônoma e construtiva, o aluno buscava atender suas necessida- des de aprendizagem, esclarecendo as dúvidas dos conteúdos e as ações necessárias para cada problema que o paciente apresentava; e, em um ambiente simulado de uma realidade de PCR de um adulto, proporcionando ao aluno o desenvolvimento de habilidades de resolução de problemas; de formulação de hipóteses; e de se engajar na descoberta da aprendizagem em RCP. ${ }^{15}$ Para tanto, adotou-se uma situação "Mega Code" (código maior), abordando o Algoritmo Universal para o atendimento de Adultos em PCR desde o Suporte Básico de Vida (SBV) até o Suporte Avançado de Vida (SAV).

Optou-se por fazer um recorte na apresentação dos resultados e discussão adotando neste momento a apresentação das avaliações feitas pelos alunos, bem como do ambiente de simulação de aprendizagem em RCP, por se entender a simulação como uma estratégia fundamental em Informática em Enfermagem para proporcionar ao aluno a experiência do cuidado virtual, questionando-o em suas ações: "o que aconteceria se...?” e ser capaz de encontrar a resposta na situação que é apresentada, sem acarretar, contudo, danos à vida do paciente.

O desenho do ambiente simulado de aprendizagem inteligente assistido por computador está fundamentado em uma arquitetura distribuída baseada em sistemas que permite a vários processos autônomos, chamados agentes inteligentes, realizarem atos de inteligência global", através do processamento local e comunicação de interprocessos. Sendo assim, esses agentes inteligentes, especialistas nas atividades que desempenham, trabalham de forma cooperativa tentando resolver um problema do melhor modo, e se constituiu essencialmente nos seguintes módulos assim estruturados e definidos (Figura 1).

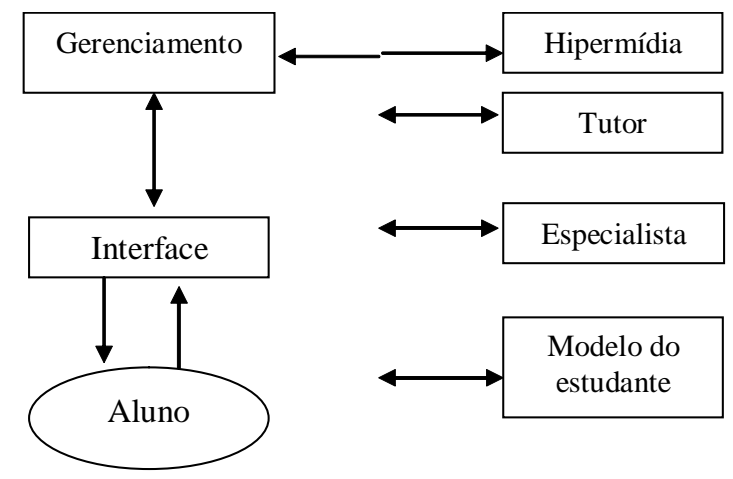

Figura 1 - Representação gráfica da estrutura do ambiente de aprendizagem assistido por computador em RCR - proposto por Sasso, 2000.

\footnotetext{
* Sabemos que cada indivíduo possui uma inteligência própria. Em um sistema multiagentes como o proposto neste estudo, a inteligência global é resultado do conjunto de "inteligências" individuais. Neste ambiente simulado os módulos: tutor, especialista e do estudante, comunicam-se, trabalhando de forma cooperativa.

Texto Contexto Enferm, Florianópolis, 2006 Abr-Jun; 15(2):231-9.
} 
Nesta estrutura, todos os agentes possuem entre eles canais de comunicação diretos. Estes canais são privados, ou seja, quando o agente hipermídia se comunica com o tutor, os agentes modelo do estudante e especialista não têm conhecimento desta conversação.

Ainda nesta arquitetura, há um agente que efetua o controle das ações dos outros agentes, organizando e distribuindo as informações. Contudo, na prática, o aluno, por meio do módulo hipermídia, é quem controla a maior parte das ações dos agentes, caracterizando assim uma estrutura de hierarquia simples. Esta arquitetura incluiu objetivos, textos e atividades de aprendizagem que estimulam os alunos a melhorarem suas habilidades de pensamento crítico e encorajam a aprendizagem auto-direcionada.

O programa na versão $a$ (alpha) foi desenvolvido a partir da Ferramenta de Autoria Toolbook versão 6.0 com seu próprio script de programação. Algumas imagens foram fotografadas e posteriormente digitalizadas, utilizando-se os programas MGI Photo Suit 1,5 e PaperCom para ambiente $W$ indows para a digitalização e o Adobe PhotoShop 5.0 para o tratamento das mesmas. Outras foram filmadas em VHS e posteriormente digitalizadas em formato AVI o que permitiu dar mais realidade às imagens, aproximando o programa da prática.
A opção pela ferramenta de autoria ToolbooK 6.0 se deu, essencialmente, pelos seguintes critérios: custo acessível; fácil manuseio; suporta outras linguagens de programação; acesso facilitado pelas universidades; contribui para encorajar a auto-aprendizagem e também possibilita que um educador possa desenvolver programas educativos de modo facilitado sem a exigência de programação pesada, utilizando os próprios scripts (roteiros) que acompanham o programa.

Por se tratar de um protótipo produzido em versão $a$, o mesmo está protegido segundo as disposições gerais da Lei n. ${ }^{\circ} 9609$ de 19 de fevereiro de 1998, que dispõe sobre a proteção da propriedade intelectual de programa de computador, sua comercialização no País, e dá outras providências. ${ }^{16}$

\section{RESULTADOS E DISCUSSÃO}

\section{O ambiente simulado em RCP}

Ao clicar no botão iniciar da tela principal, o aluno verá outra tela, contendo os botões e opções do programa com uma breve explicação de como ele funciona e está estruturado. Esta tela solicita ao aluno seu nome, para que o programa possa realizar as avaliações de aprendizagem de forma personalizada (Figura 2).

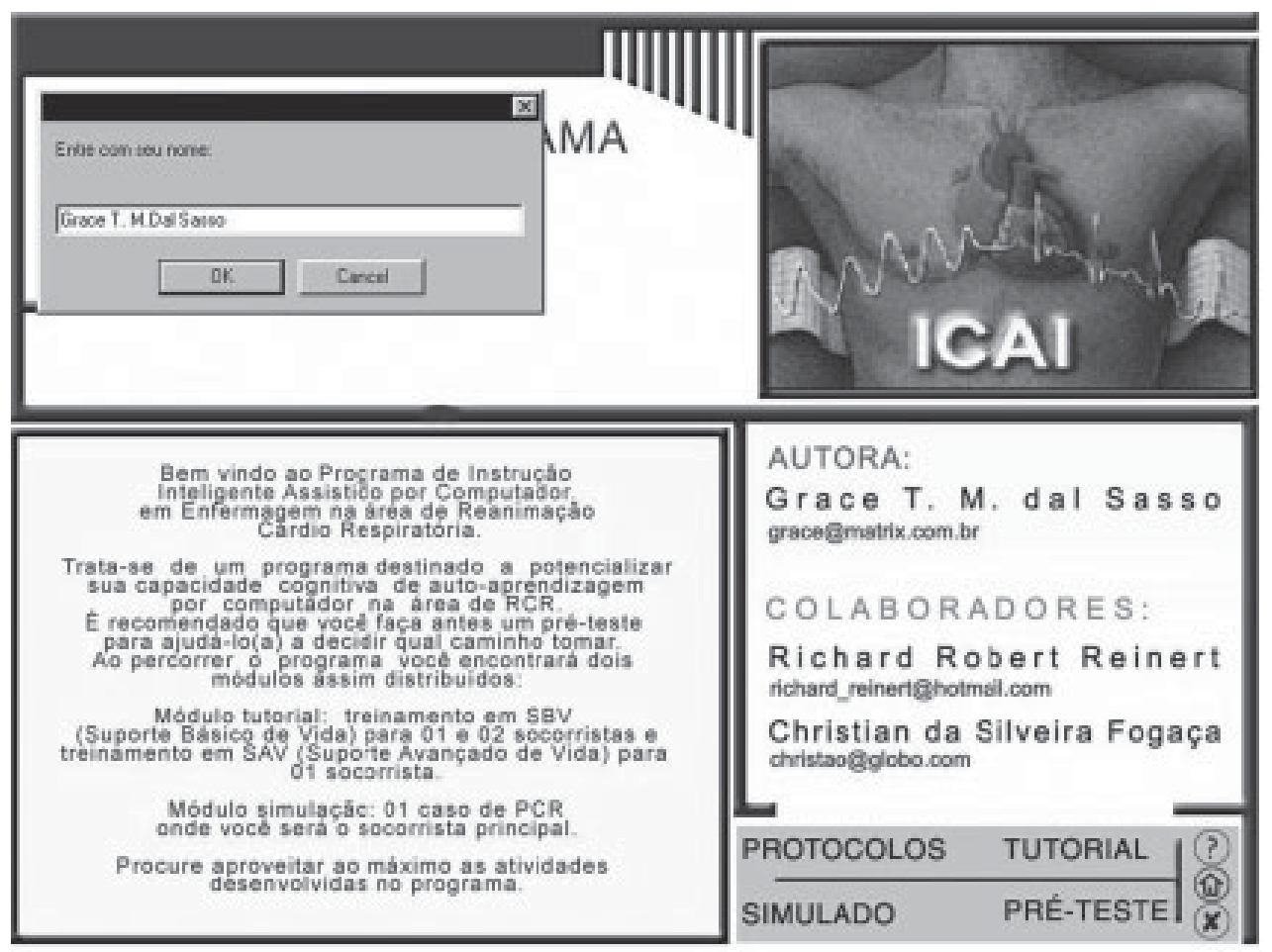

Figura 2 - Tela entrada com demonstração das opções do programa. 
Caso tenha interesse em aprofundar as explicações do programa, o aluno poderá clicar no botão ajuda ou navegar pelo programa inicialmente ou ainda, fazer o pré-teste, ou seja, poderá optar pelo caminho que achar mais conveniente. $\mathrm{O}$ recomendado é que ele faça um pré-teste para saber em que nível se encontra, contudo, ele tem a liberdade de ir diretamente no Módulo Tutorial ou Simulação. Poderá também sair do programa, no momento que achar conveniente.

No ambiente simulado, foi necessário definir as situações, as imagens, as etapas do processo de aprendizagem, as ações do usuário, a bibliografia a ser consultada e os links para a Internet que fariam parte do programa.

O aluno pode escolher o processo de avaliação promovido pelo programa, durante a sua utilização, entre integral, formativa e/ou diagnóstica. O programa apresenta também uma pontuação (escore) de desempenho do aluno categorizada, segundo as diferentes fases da resolução do caso (tomada de decisão) e de acordo com a forma de avaliação escolhida. A situação de PCR se inicia com o aparecimento súbito de uma pessoa fora da área hospitalar, aparentemente tendo um quadro de Infarto Agudo do Miocárdio.

É apresentada uma breve descrição do caso, sem detalhes clínicos de monta (nenhuma pista foi dada sobre a etiologia da condição atual do paciente).O programa tem passagem automática de tempo, desvios aleatórios (possibilitando a evolução não previsível da situação), inclusão de imagens, contendo sinais físicos e biológicos (ausência de consciência, pulso e PA, ECG, intubação, ventilação, entre outros).

De modo a forçar um papel mais ativo por parte do aluno no processo de tomada de decisão e assistência direta ao paciente, utilizou-se o artifício de que o enfermeiro será o responsável por todas as condutas com o paciente, até um determinado ponto, quando, então, a vítima é conduzida ao hospital e recebe a continuidade da assistência pela equipe de saúde, criando assim novas oportunidades para simular a conduta de enfermagem. Deste modo, impulsiona-se a convergência para o educar-cuidar.

Após a apresentação inicial do caso no ambiente simulado, o aluno tem que tomar uma série de decisões relativas à avaliação do estado geral do paciente $\mathrm{e}$ seus parâmetros vitais e intervenções prioritárias. Dependendo da resposta do aluno e por se tratar de um processo dinâmico de aprendizagem, o programa estimula o aluno a alcançar o objetivo de reanimação da vítima, proporcionando, assim, uma atitude positiva frente aos desafios gerados pelo programa. O próprio aluno vai acompanhando o tempo decorrido do atendimento e os parâmetros vitais do paciente.

No ambiente simulado, o aluno não poderá deixar de concluir o caso e retroceder no programa. Uma vez iniciado, o aluno deverá ir até o final da situação, para, então reiniciar novamente. Pode, contudo, sair da situação simulada e escolher outra opção para aprofundar seu processo de aprendizagem no menu como, por exemplo, o tutorial, navegar via Web e buscar ajuda.

As simulações fazem uso de todos os recursos disponíveis no programa, inclusive sumários do caso, painéis dos resultados das intervenções e comentários sobre cada resposta (Figuras 3 e 4).

Os textos de comentário e revisão das simulações são ricos e elucidativos, comentando aspectos básicos e clínicos da situação apresentada de PCR, com informações atualizadas. $\mathrm{O}$ aluno poderá repetir as situações de RCR tantas vezes quanto desejar e os resultados podem ser impressos, nesta versão.

Visando estimular uma atitude positiva do aluno no seu processo de ensino-aprendizagem, no módulo tutorial, o aluno sempre consegue reanimar a vítima de PCR. Contudo, no ambiente simulado, o aluno pode experenciar tanto a reanimação da vítima por um caminho mais curto ou mais longo, dependendo de sua atuação quanto a experiência de morte do paciente (Figuras 3 e 4).

Desde o início da simulação, o programa promove o máximo de interação com a situação de aprendizagem, uma vez que o aluno pode optar pelo ambiente que deseja atuar, o tipo de avaliação que deseja obter e em que micromundo quer entrar primeiro: no Tutorial ou na Simulação. A motivação do aluno é essencial ao processo de ensino/aprendizagem, pois ela tem o potencial para afetar todos os estágios do ciclo de integração da tecnologia educacional informatizada proposta.

Portanto, todas estas etapas tornam a interface inteligente e tem por objetivo saber o que ensinar, a quem ensinar e como fazê-lo, dando-se assim, a convergência entre o educar-cuidar. 


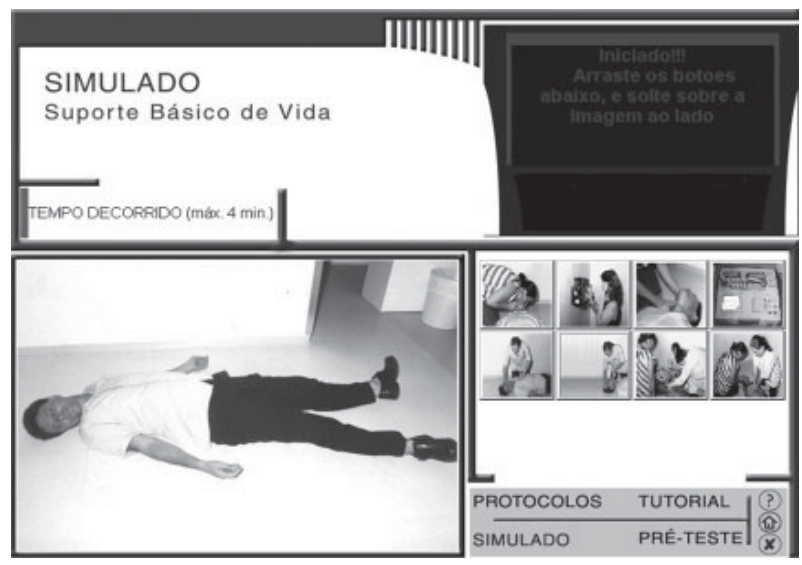

Figura 3 - Tela inicial ambiente simulado.

As mensagens de erro têm uma função importante e são abordadas em área específica da tela. Estas mensagens de erro não são apenas feedback que explicam as respostas incorretas do aluno em relação ao conteúdo. São apresentadas quando o aluno fez entradas inapropriadas que o computador não pode aceitar e/ou interpretar. As mensagens de erro são claramente estabelecidas na tela em local específico, de modo que a sua atenção esteja dirigida para esta informação no ambiente simulado.

Foi projetada uma caixa em torno das mensagens fornecidas pelo programa no Módulo Simulação com uma barra de rolagem (Figura 4), permitindo que o usuário revise os passos de suas ações, reflita sobre seus erros e mude suas ações.

Durante a avaliação, o programa está centrado nos seguintes erros mais freqüentemente cometidos, durante a aprendizagem em RCP: a seqüência correta

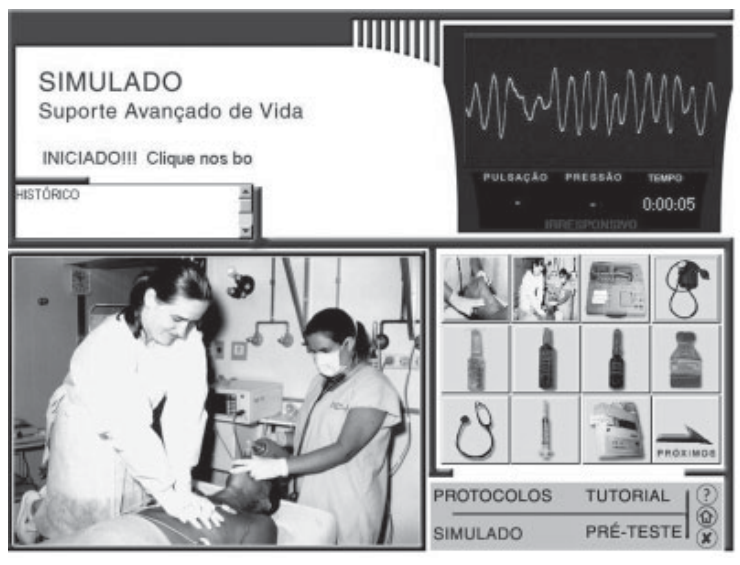

Figura 4 - Tela simulação em SAV.

das etapas de SBV e SAV; procedimentos que são desempenhados sem necessidade; drogas usadas na RCP; reconhecimento dos ritmos no Monitor tais como: regular e sinusal, taquicardia ventricular sem pulso, fibrilação ventricular, assistolia, extrassístoles ventriculares, atividade elétrica sem pulso e bloqueio átrio-ventricular total; interrupção das manobras de reanimação; a não realização de compressões torácicas na AESP (Atividade Elétrica sem Pulso) e o tempo durante as manobras de RCP.

Independentemente da escolha do aluno, caso opte, por exemplo, em não fazer a Simulação, mas apenas o pré-teste, o programa fornecerá esta avaliação (Figura 5). Ainda, procurou-se vincular a entrada do aluno no programa a uma forma de avaliação de modo que o mesmo possa contribuir com o processo ensino/aprendizagem do aluno.

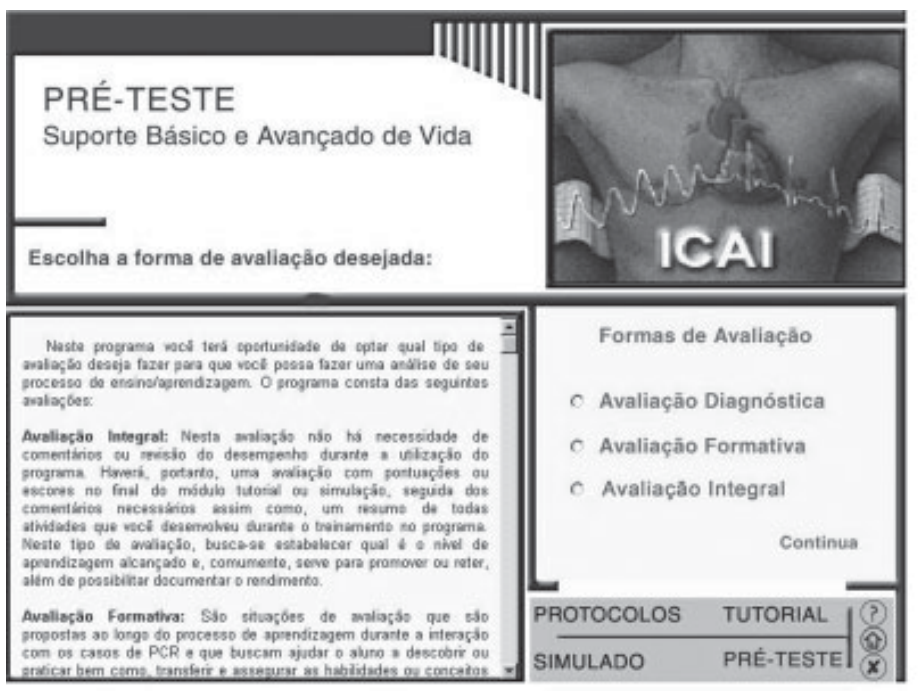

Figura 5 - Tela formas de avaliação. 
Contudo, o aluno somente fará o pós-teste depois de percorrer a simulação. O objetivo de tal procedimento é de estimulá-lo a explorar ao máximo o que é oferecido no programa. É importante salientar que a oportunidade de errar é fundamental no processo de auto-aprendizagem construtiva. É algo que, por meio do computador se pode oferecer sem causar prejuízos reais à vida do cidadão e também auxilia o aluno a adquirir auto-confiança. Assim, o computador poderá captar cada falha do aluno como oportunidade para que o mesmo corrija os seus erros, o que será possível por meio de outra entrada no programa.
Assim sendo, o ambiente de aprendizagem informatizado é capaz de fornecer um percentual de acerto nas questões de pré-teste e pós-teste, o tempo que o usuário levou para fazer os testes e, no módulo simulação, um escore geral personalizado tanto do módulo simulação quanto do módulo tutorial, bem como, um roteiro de observações das seqüências desenvolvidas pelo usuário, durante o módulo simulação e das recomendações fornecidas pelo programa em cada etapa.

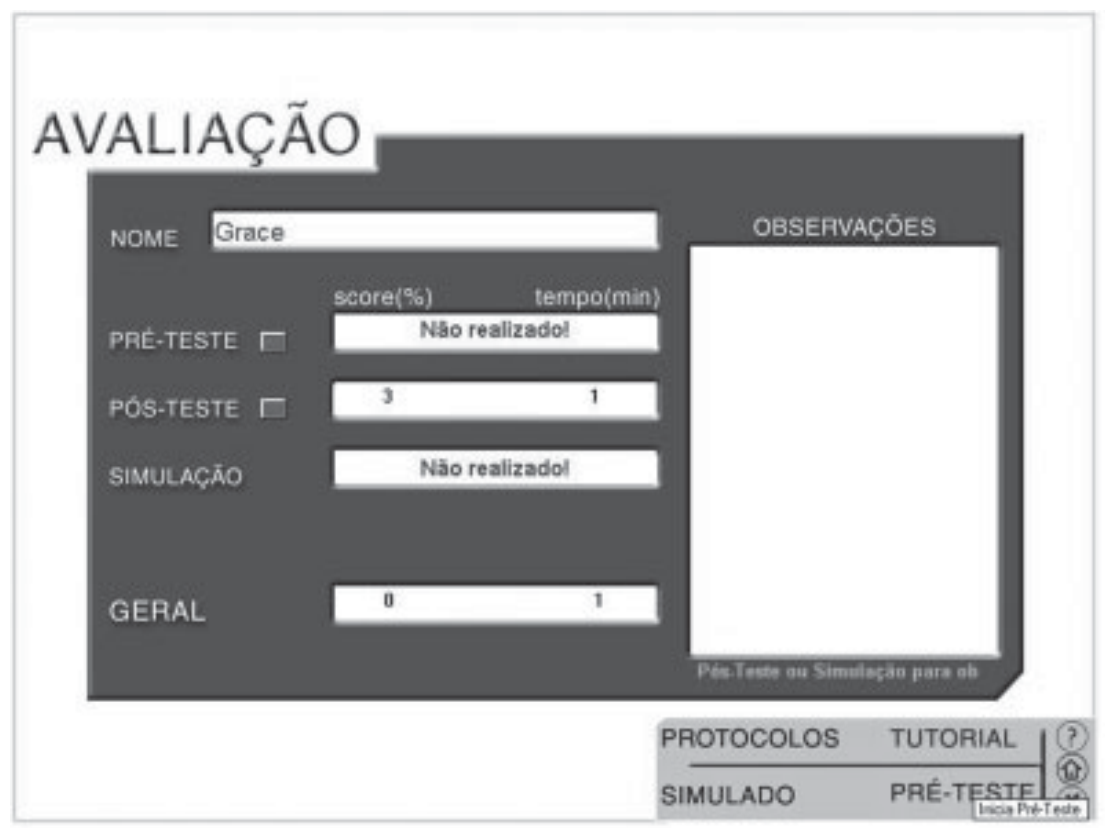

Figura 6 - Resumo da avaliação.

\section{As avaliações dos alunos}

À medida que o programa foi sendo desenvolvido e discutido, observou-se a importância de um feedback do educador sobre os desempenhos e avaliações dos alunos, bem como sobre as questões de pré e pós-teste do programa, a fim de estimular e encorajar a aprendizagem auto-dirigida. Assim, foi disponibilizado um e-mail no programa para que o aluno pudesse enviar dúvidas e/ou comentários, caso sentisse necessidade. Esta é uma atividade que requer mais tempo, pois é preciso que o professor responda a cada aluno individualmente. Antes de o aluno interagir com o ambiente, é necessário, contudo, explicar a ele como funciona e quais os objetivos que se pretende atingir. É preciso, então, deixá-lo interagir um pouco com o programa, clarear dúvidas com o educador relacionadas ao conteúdo, ao computador e aos botões e, então, posteriormente estimulá-lo a usar.
Outro aspecto a ser ressaltado, refere-se ao fato de que para os alunos que participaram deste estudo, a aprendizagem através do computador é vista como um paradoxo, pois, ao mesmo tempo em que acham estimulante e inovador desenvolver atividades desta forma, individualmente, sentem-se dependentes do professor e desejam obter respostas prontas, quando desafiados pelo programa. Além disso, para muitos, poderá ser a primeira vez que utilizam o computador para esse fim e, portanto, será necessário um treinamento básico sobre como utilizá-lo, ou seja, o desenvolvimento de competência para a inovação mediante os avanços da ciência e os recursos para educação.

O próprio conteúdo de RCP é ameaçador, pois coloca o aluno de frente com uma situação de desafio em salvar uma vida e este estímulo provoca o imaginário do aluno, colocando-o realmente como se estivesse vivenciando aquela situação. 
Desta forma, a avaliação interna dos 3 (três) alunos que participaram do estudo considerou 14 itens, de um total de 19 questões fechadas com escala de valores correspondentes a excelente, bom, regular, ruim e não se aplica.

Receberam valor de qualidade excelente por $100 \%$ dos alunos itens relacionados a: expectativa em relação ao programa, a forma de apresentação das informações e ajuda, a interface entre o aluno e o programa, o nível de independência promovido, as animações, o grau de complexidade, os benefícios adquiridos, as avaliações proporcionadas, as informações claras e concisas, a organização lógica do conteúdo e das informações, a definição clara do objetivo, o mecanismo de feedback explorado no programa e o estímulo à aprendizagem.

Consideraram ainda com valor bom por também 100\% dos alunos o item acesso facilitado, especialmente porque o programa exige uma certa quantidade de memória RAM que o tornou difícil rodar no computador disponível no momento da avaliação. Por sugestão dos alunos, foi acrescentado ainda ao programa os cuidados que um profissional deve ter, ao atender uma Parada Cárdio-Respiratória na rua ou em qualquer outro ambiente extra-hospitalar, sem Equipamentos de Proteção Individual (EPIs). Nenhum item do processo de avaliação foi caracterizado como regular, ruim ou não se aplica, demonstrando que este grupo do estudo gostou de aprender com os recursos da Informática.

O programa, a partir deste estudo, demonstra a perspectiva de que ele pode estimular a autoconfiança porque proporciona ao aluno um sentimento de controle sobre o que ele está aprendendo. Neste sentido, se fazem necessários o desenvolvimento de novos estudos de validação externa, na tentativa de comprovar se este programa leva o aluno a ser um participante mais ativo na sua educação.

\section{CONSIDERAÇÕES FINAIS}

De forma geral e de acordo com as avaliações apresentadas, este estudo demonstrou que um ambiente simulado de aprendizado assistido por computador possibilita focalizar a atenção do aluno no problema, eliminando as questões éticas da situação real, de estresse para o aluno e de risco para o cidadão; permite a manipulação controlada da situação de cuidado do paciente em PCR, com resultados que podem ser previsíveis; evita que o paciente sofra danos reais, devido a eventuais falhas de decisão do profissional e/ ou aluno; assegura a padronização do cuidado em um situação semelhante à prática; e pode ser usado para avaliar as aprendizagens afetiva e cognitiva.

Ainda, das avaliações dos alunos e do processo de produção tecnológica, o ambiente simulado proporciona dois tipos de aprendizagem: o relacional, em que o aluno adquire determinadas habilidades, permitindo-lhe fazer relações com outros casos de RCP ou outras fontes de informação ao poder registrar suas dúvidas, consultar websites de referência na área, receber e enviar e-mail para outros alunos. Neste caso, a aprendizagem se processa somente da interação do aluno com a tecnologia, gerando um processo de aprendizagem mais individual; o criativo, no qual o aluno faz associação às criações de novos esquemas mentais, possibilitando a interação entre pessoas e tecnologias e compartilhando objetivos comuns. Neste caso, a aprendizagem se processa de forma mais participativa.

Por outro lado, a principal dificuldade da simulação percebida no desenvolvimento da produção do prgrama, repousa em sua credibilidade e na transferência de aprendizagem para a vida real, pois, na interface entre o aluno e o computador, o teclado e o mouse são muito diferentes do que se usa na vida real. Contudo, parte deste problema pôde ser amenizada introduzindo, por exemplo, pressão de tempo. Isto é, o aluno, ao interagir cognitivamente com as cenas no programa, dispõe de um tempo limitado para executar adequadamente as ações, de acordo com o que acontece na vida real.

Ao buscar esta convergência do educar-cuidar, com simulação por computador para ensinar enfermagem clínica, o processo ensino-aprendizagem se desenvolve simultaneamente em dois ou mais domínios, tais como, psicomotor e cognitivo ou cognitivo e afetivo, proporcionando maior rapidez e precisão nas decisões clínicas em RCP com incorporação de novos valores em termos de tecnologias e inovação.

Como mediador entre o sujeito e o mundo real, o ambiente simulado de aprendizagem assistida por computador, constitui-se em uma espécie de lente, através da qual o aluno é capaz de ver a realidade simulada e operar sobre ela. É proporcionado ao aluno uma oportunidade nova e estimulante de aprendizagem.

Este tipo de tecnologia, portanto, não substitui o educador, mas contribui para modificar suas funções e reforça a responsabilidade do aluno com o seu próprio desempenho. $\mathrm{O}$ educador se transforma no estimulador da curiosidade do aluno, por querer co- 
nhecer e buscar informação mais relevante às necessidades de aprendizagem estimuladas pelos recursos da Informática. Num segundo momento, considera o processo de apresentação dos resultados pelos alunos de acordo com o estabelecido na estrutura multi-agentes para o módulo tutorial e simulado, depois questiona os dados apresentados a partir das atividades registradas pelo aluno durante a interação com o programa, contextualiza os resultados e adapta-os à realidade dos alunos. Este processo de feedback ao aluno não se resume as respostas que o programa fornece mas, em um ir e vir constantes entre o educador, o aluno e o programa. Transforma informação em conhecimento e conhecimento em saber, em vida, em sabedoria - o conhecimento com ética. ${ }^{17}$

Desta forma, a ação maior do educador, ao integrar em sua prática, ambientes simulados inteligentes de aprendizagem assistida por computador, se dá em ser um desencadeador, um provocador e um construtor de uma prática específica e qualificada que objetiva promover o aluno, no processo ensino/aprendizagem em RCP. O educador estando virtualmente ou fisicamente presente, estará complementando, fazendo e convivendo com suas próprias descobertas e inovações, bem como com a dos alunos, num processo de crescimento e interação recíprocos.

\section{REFERÊNCIAS}

1 Martins HS, Neto AS, Velasco IT. Emergências clínicas baseadas em evidências. In: Damasco MT, Timerman S. Novas técnicas em ressuscitação cárdiopulmonar. São Paulo: Atheneu; 2005. p.17-24.

2 Graves J, Corcoran S. The study of nursing informatics. Image Nursing Scholarship. 1989 Winter 21(4): 227-31.

3 Sasso GTMD, Barbosa SFF. Perspectivas futuras à informática em enfermagem: a aplicabilidade dos ambientes hipermídia no processo ensino-parendizagem. Texto Contexto Enferm. 2000 Jan-Abr; 9 (1): 79-92.

4 Panqueva A HG. Ingenieria de software educativo. Colômbia: Uniandes; 1992.
5 Abedellah FG, Levine E. Better patient care through nursing research. New York: MacMillan; 1965.

6 Ministério da Saúde (BR), Conselho Nacional de Saúde, Comitê Nacional de Ética em Pesquisa em Seres Humanos. Resolução No 196 de 10 de outubro de 1996: diretrizes e normas regulamentadoras de pesquisa envolvendo seres humanos. Brasília (BR): O Conselho; 1996.

7 Matui J. Construtivismo: teoria construtivista sóciohistórica aplicada ao ensino. São Paulo: Moderna; 1995.

8 Vygotsky LS. A formação social da mente. São Paulo: Martins Fontes; 1991.

9 Piaget J. A construção do real na criança. Rio de Janeiro: Zahar; 1970.

10 Goldstein I. The genetic graph: a representation for the evolution of procedural knowledge. Interna. Manmachine Studies. 1979 Jan; 11 (1): 51-77.

11 Eraut M. The international encyclopedia of educational thecnology. Oxford: Pergamon Press; 1989.

12 Arnold J, Pearson G. Computer applications in nursing education and practice. New York: Betther Graphics; 1992.

13 Rouse DP. Creating in interative multimedia computerassisted instruction program. Computers in Nursing. 1999. Jul-Aug; 17 (1): 171-9.

14Soon KH. The effects of internet-based distance learning in nursing. Computers in Nursing Philadelphia. 2000 JanAbr; 18 (1): 19-25.

15 Arnold J. Custom item analyses interface with a diagnose gerontological nursing simulation. Nursing Informatics. 1993 Sep-Oct; 15 (2): 541-4.

16 Associação Brasileira de Empresas de Software. Proteção de propriedade intelectual de programa de computador [acesso em 2003 Dez 20]. Disponível em: http:// www.abes.org.br/

17 Moore MG, Kearsley G. Distance education: a systems view. Belmont (USA): Wadsworth Publishing Company; 1996. 